\title{
Biogenic amines degradation by Lactobacillus plantarum: toward a potential application in wine
}

\author{
Vittorio Capozzi 1,2, Pasquale Russo ${ }^{1,2}$, Victor Ladero ${ }^{3}$, María Fernández $^{3}$, Daniela Fiocco ${ }^{4}$, Miguel A. Alvarez ${ }^{3}$, \\ Francesco Grieco ${ }^{5}$ and Giuseppe Spano ${ }^{1 *}$
}

${ }^{1}$ Department of Food Science, University of Foggia, Foggia, Italy

2 Promis Biotech srl, Facoltà di Agraria, Università degli Studi di Foggia, Foggia, Italy

3 Instituto de Productos Lácteos de Asturias, CSIC, Villaviciosa, Spain

${ }^{4}$ Department of Biomedical Sciences, University of Foggia, Foggia, Italy

${ }^{5}$ Institute of Science of Food Production, National Research Council, Lecce, Italy

Edited by:

Giovanna Suzzi, Università degli Studi

di Teramo, Italy

\section{Reviewed by:}

Svetoslav Todorov, University of Sao

Paulo, Brazil

Eveline Bartowsky, The Australian

Wine Research Institute, Australia

\section{*Correspondence:}

Giuseppe Spano, Department of Food

Science, University of Foggia, Via

Napoli 25, Foggia 71122, Italy.

e-mail:g.spano@unifg.it
Biogenic amines (BA) in wine represent a toxicological risk for the health of the consumer, with several trade implications. In this study 26 strains of Lactobacillus plantarum were analyzed for their ability to degrade BA commonly found during wine fermentation. Two strains of $L$. plantarum were selected in reason of their ability to degrade putrescine and tyramine. The degradation was assessed in vitro, both in presence of the BA and in presence of the specific chemical precursor and of producer bacteria. The two L. plantarum biotypes were found capable to work synergically. In addition, the survival in wine-like medium and the aptitude to degrade malic acid after alcoholic fermentation of the selected L. plantarum strains was analyzed. Our results suggest the potential application of wine L. plantarum strains to design malolactic starter cultures able to degrade BA in wine.

Keywords: lactic acid bacteria, amine degradation, biogenic amines, malolactic fermentation, wine, Lactobacillus plantarum, putrescine, tyramine

\section{INTRODUCTION}

Biogenic amines (BA) are low molecular weight organic bases with aliphatic, aromatic, and heterocyclic structures commonly found in fish, fish products, meat, dairy products, vegetables, wine, cider, and beer (Suzzi and Gardini, 2003; Spano et al., 2010). In general, foods likely to contain high levels of BA are fermented foods or foodstuff exposed to microbial contamination during food process or storage (Ali, 1996). Histamine, tyramine, cadaverine, 2-phenylethylamine, spermine, spermidine, putrescine, tryptamine, and agmatine are considered to be the most important BA occurring in foods. The main bacteria responsible for BA production in fermented food matrices are the lactic acid bacteria (LAB; Lonvaud-Funel, 2001). In fact, LAB can catabolize (principally decarboxylate) amino acids into amine-containing compounds. The physiological role of BA synthesis mainly seems to be related to defense mechanisms used by bacteria to withstand acidic environments (Spano et al., 2010).

Indigenous BA compounds are also naturally produced in different human tissues because of their biological role in processes such as synaptic transmission, blood pressure control, allergic response, and cellular growth control (Russo et al., 2010). The gastro-intestinal tract, as a function of dietary intake of food containing BA, therefore represents an exogenous source of these molecules for humans. This exogenous source of BA can provoke high levels in the human organism, and in reason of their importance in physiological processes, with negative consequences to human health (Ladero et al., 2010; Russo et al., 2010). Human sensitivity fluctuates according to the correct functioning of the detoxification systems since BA are generally metabolized in the human gut through the action of amine oxidases (Spano et al.,
2010). Under physiological conditions this system has a protective role against the absorption of dietary BA. For this reason, in individuals with a pathological deficiency of amine oxidases activities, the ingestion of food products containing excess of BA may lead to high levels of BA in the organism (Kuefner et al., 2004). Additionally, the ethanol and some drugs have been found to inhibit the detoxification systems (Zimatkin and Anichtchik, 1999; Horton et al., 2005). In the wine industry, the occurrence of BA has been receiving increasingly attention in reason of the potential threats of toxicity to humans, connected with alcohol content (Smit et al., 2008). There are trade implications due to the recommended or suggested existing limits for histamine in wine in some European countries such as Germany $(2 \mathrm{mg} / \mathrm{l})$, Holland $(3 \mathrm{mg} / \mathrm{l})$, Finland $(5 \mathrm{mg} / \mathrm{l})$, Belgium $(5-6 \mathrm{mg} / \mathrm{l})$, France $(8 \mathrm{mg} / \mathrm{l})$, Switzerland, and Austria (10 mg/l; Smit et al., 2008). In addition, last year, the Panel on Biological Hazards of the European Food Safety Authority release a Scientific Opinion on risk based control of BA formation in fermented foods 9 [EFSA Panel on Biological Hazards (BIOHAZ), 2011], testifying the attention of European institutions to the subject.

In reason of the toxicity and of the existing legislative limits, several technological strategies have been proposed in order to control BA in foods (Naila et al., 2010). The main measure to prevent BA formation is the microbial control through cold treatments. However, it is difficult to operate with low temperature in the case of fermented foods, where a microbial growth is crucial to obtain the final products. Secondary control measures to prevent BA formation in foods or to reduce their levels once formed need to be considered as alternatives. Methods to limit microbial growth may include hydrostatic pressures, irradiation, controlled atmosphere 
packaging, or the use of food additives (Naila et al., 2010). Furthermore, BA could be controlled, especially in fermented foods, modulating microbial resources. Indeed, fermented foods producers commonly utilize a specific starter culture, that is "a microbial preparation of large numbers of cells of at least one microbial species to be added to a raw material to produce a fermented food by accelerating and steering its fermentation process" (Leroy and De Vuyst, 2004). In general, the choice of starter cultures is crucial to guarantee the quality of the final products and microbial starter unable to produce BA might dominates the autochthonous microbiota, reducing the occurrence of BA producers (Dapkevicius et al., 2000; Latorre-Moratalla et al., 2007; Naila et al., 2010; Spano et al., 2010). Additionally, starter may control BA in food via their amine oxidase activity because oxidizes BA into aldehyde, hydrogen peroxide, and ammonia (Suzzi and Gardini, 2003; Naila et al., 2010; Spano et al., 2010). In red wine, the most abundant amines are usually putrescine, histamine, tyramine, and cadaverine (Beneduce et al., 2010), the last being considered the most important reason for wine intolerance (Konakovsky et al., 2011). Inoculation with starter cultures that are unable to produce BA is a feasible option for the control of these chemical substances in wine (Martín-Álvarez et al., 2005; Spano et al., 2010). However, it does not represent the definitive solution when the dominance of starter cultures on the indigenous BA-producer microflora is not sufficient. Recently, García-Ruiz et al. (2011) isolated some LAB from wine and other oenological source and tested their ability to degrade BA. Whereas a negative influence of the wine matrix was observed, their findings indicated a potential application of wine LAB in order to reduce BA in wine (García-Ruiz et al., 2011).

In this paper we report the selection of autochthonous strains of Lactobacillus plantarum able to degrade BA and their suitability to be used as malolactic starter in wine production.

\section{MATERIALS AND METHODS BACTERIAL STRAINS AND GROWTH CONDITIONS}

The LAB strains included in this study were routinely cultured on MRS (de Man-Rogosa-Sharp, Oxoid, Milan, Italy) medium. The $\mathrm{pH}$ of the medium was adjusted to $\mathrm{pH} 5.8$ with $\mathrm{KOH}$ before sterilization for $15 \mathrm{~min}$ at $121^{\circ} \mathrm{C}$. Samples from 10 natural vinifications of "Nero di Troia" wines were aseptically collected at the early stages of malolactic fermentation from winery located in Apulia region (Italy). For microbiological analyses, $10 \mathrm{ml}$ of each sample were homogenized with $90 \mathrm{ml}$ of a saline-peptone water, after which serial dilutions were prepared. For the isolation of LAB, MRS agar containing $100 \mathrm{mg} / \mathrm{l}$ of cycloheximide was used, and the plates were incubated under anaerobic conditions $(\mathrm{BBL}$, GasPack-System) at $30^{\circ} \mathrm{C}$ for $72 \mathrm{~h}$. Isolates were identified as bacilli and putative $\mathrm{LAB}$ by positive Gram staining and negative catalase assay. All strains were stored at $-80^{\circ} \mathrm{C}$ in MRS supplemented with glycerol $(20 \% \mathrm{v} / \mathrm{v})$.

\section{STRAINS IDENTIFICATION}

Genomic DNA of putative LAB was isolated using the Microbial DNA extraction kit (Cabru, Milan, Italy) according to manufacturer's procedure.

Preliminary identification of $L$. plantarum strains was performed by amplification of the recA gene. Primers planF and
pREV were used in the PCR tests (Torriani et al., 2001). For PCR amplification about $50 \mathrm{ng}$ of genomic DNA were added to a $50 \mu \mathrm{l}$ PCR mixture and amplified with Taq DNA Polymerase (Qiagen, Milan, Italy). The temperature profile was as follows: $94^{\circ} \mathrm{C}$ for $5 \mathrm{~min} ; 30$ cycles of $94^{\circ} \mathrm{C}$ for $0.5 \mathrm{~min}, 46^{\circ} \mathrm{C}$ for $0.5 \mathrm{~min}, 72^{\circ} \mathrm{C}$ for $0.5 \mathrm{~min} ; 72^{\circ} \mathrm{C}$ for $5 \mathrm{~min}$. Furthermore, the isolated strains were identify by partially sequencing the $16 \mathrm{~S}$ rRNA-encoding gene. Most of the gene encoding the $16 \mathrm{~S}$ ribosomal RNA was amplified by PCR using primers $\mathrm{pA}$ and $\mathrm{pH}$ according to Edwards et al. (1989). The amplicons were purified using QIAquick PCR Purification Kit (Qiagen, Milan, Italy) and sequenced. The resulting sequences were compared with sequences available at NCBI database (GenBank) using the standard nucleotide-nucleotide homology search basic local alignment search tool (BLAST; http://www.ncbi.nlm.nih.gov/BLAST).

In order to verify if the bacteria analyzed in this study harbor genes encoding enzymes involved in production of BA such as tyramine, histamine, and putrescine, a multiplex-PCR-based assay was carried out to detect the presence of tyrosine decarboxylase $(t d c)$, histidine decarboxylase $(h d c)$, and ornithine decarboxylase (odc) genes (Coton et al., 2010). About $50 \mathrm{ng}$ of genomic DNA was added to a $50 \mu \mathrm{l}$ PCR mixture and amplified with Taq DNA Polymerase (Qiagen, Milan, Italy). The reaction mix was cycled through the following temperature profile: $94^{\circ} \mathrm{C}$ for $5 \mathrm{~min} ; 15$ cycles of $94^{\circ} \mathrm{C}$ for $1 \mathrm{~min}, 55^{\circ} \mathrm{C}$ for $1.3 \mathrm{~min}, 72^{\circ} \mathrm{C}$ for $1 \mathrm{~min} ; 12$ cycles of $94^{\circ} \mathrm{C}$ for $1 \mathrm{~min}, 58^{\circ} \mathrm{C}$ for $1.3 \mathrm{~min}, 72^{\circ} \mathrm{C}$ for $1 \mathrm{~min} ; 72^{\circ} \mathrm{C}$ for $5 \mathrm{~min}$.

PCR fragments were analyzed by agarose gel electrophoresis carried out by loading $10 \mu \mathrm{l}$ of sample on $1.2 \%$ agarose gels.

\section{ANALYSIS OF BA BY HPLC AND PRELIMINARY SCREENING}

In order to test the individual degrading capacity of isolated strains, BA concentration was quantified in MRS broth samples supplemented with putrescine $(1 \mathrm{mM})$, tyramine $(1 \mathrm{mM})$, cadaverine $(1 \mathrm{mM})$, or histamine $(2.5 \mathrm{mM})$ after $24 \mathrm{~h}$ with or without strain inoculation $\left(2 \times 10^{6} \mathrm{CFU} \mathrm{ml}^{-1}\right.$; total volume $\left.20 \mathrm{ml}\right)$. One milliliter of each sample was centrifuged and the supernatant was filtered through $0.45 \mu \mathrm{m}$ PTFE filters (VWR, USA). Five microliters were derivatized using dansyl chloride, separated, and analyzed using the conditions described by Ladero et al. (2011).

\section{VALUATION OF DEGRADING BACTERIA IN VITRO}

MRS broth samples $(1 \mathrm{ml})$ supplemented with putrescine $\left(1 \mathrm{mmoll}^{-1}\right)$, tyramine $\left(1 \mathrm{mmoll}^{-1}\right)$, cadaverine $\left(1 \mathrm{mmoll}^{-1}\right)$, and histamine $\left(2.5 \mathrm{mmoll}^{-1}\right)$ were collected after $24 \mathrm{~h}$ with and without degrader strain inoculation (starting from an $\mathrm{OD}_{600}$ of about 0.05 ; total volume 11 ). In a separate trial the two strains were co-inoculated (starting from an $\mathrm{OD}_{600}$ of about 0.05 for each strain; total volume $1 \mathrm{l})$. MRS broth samples (1 ml) supplemented with tyrosine $\left(15 \mathrm{mmoll}^{-1}\right)$ or agmatine $\left(4.38 \mathrm{mmoll}^{-1}\right.$; Arena et al., 2011) were collected after $24 \mathrm{~h}$ from inoculation with degrader strain (starting from an $\mathrm{OD}_{600}$ of about 0.05 ) and producer strain (starting from an $\mathrm{OD}_{600}$ of about 0.05 ; total volume 11). BA content was determined as previously indicated and degradation activity was expressed as a percentage of the control without degrader strain. The producer strains were Lactobacillus brevis IOEB 9809 (Lucas et al., 2007; Arena et al., 2010) and Enterococcus 
faecium OT23 (Capozzi et al., 2011), respectively for putrescine and tyramine.

\section{SURVIVAL IN WINE-LIKE MEDIUM AND MALOLACTIC FERMENTATION}

The composition of the synthetic must and winemaking conditions were based on the protocol described by Capozzi et al. (2010). All components were purchased from Sigma, Milan, Italy. The synthetic musts contained glucose $\left(96.5 \mathrm{gl}^{-1}\right)$, fructose $\left(108.5 \mathrm{gl}^{-1}\right)$, DL-malic acid $\left(10 \mathrm{gl}^{-1}\right)$, L-tartaric acid $\left(2 \mathrm{gl}^{-1}\right)$, ammonium chloride $\left(0.2 \mathrm{gl}^{-1}\right)$, and yeast carbon base $\left(11.7 \mathrm{gl}^{-1}\right) ; \mathrm{pH}$ was adjusted to 3.5 with $\mathrm{NaOH}$. The must was clarified and sterilize by filtration through a $0.22 \mu \mathrm{m}$ pore size filter (Millipore, Italy). The must was inoculated at the concentration of $10^{6}$ colony-forming unit (CFU) $\mathrm{ml}^{-1}$ with a commercial yeast culture (Saccharomyces cerevisiae strain AWRI R2, Maurivin, Australia), and alcoholic fermentation was performed at $22^{\circ} \mathrm{C}$ for $22-30$ days. Then, the wine was clarified by filtration through a $0.22 \mu \mathrm{m}$ pore size filter (Millipore, Italy) to remove yeasts. After filtration, the physico-chemical properties of the wine-like medium were: $12.1 \%(\mathrm{v} / \mathrm{v})$ ethanol, $4.9 \mathrm{~g}$ of $\mathrm{L}$-malic acid per liter, $\mathrm{pH} 3.5$. Wine was stored at $4^{\circ} \mathrm{C}$ until required for further experiments. MLF was initiated by direct inoculation with L. plantarum strains grown at $\mathrm{pH} 3.5$ for $16 \mathrm{~h}$ $\left(\mathrm{OD}_{600 \mathrm{~nm}}=0.6\right)$ to a final concentration of $2 \times 10^{6} \mathrm{CFU} \mathrm{ml}^{-1}$ in $50 \mathrm{ml}$ of wine. A control without inoculation was performed to verify any spontaneous MLF. Thereafter, the containers were incubated at $18^{\circ} \mathrm{C}$. Bacterial numeration was performed by counting cells (CFU ml ${ }^{-1}$ ) spread on agar plates of MRS, $\mathrm{pH} 5.8$, and incubated under anaerobic conditions (BBL, GasPack-System) at $30^{\circ} \mathrm{C}$ for $72 \mathrm{~h}$. The concentration of $\mathrm{L}$-malic acid was determined with the Boehringer enzymatic kit (Mannheim, Germany) according to the manufacturer.

\section{RESULTS \\ IDENTIFICATION OF L. PLANTARUM WINE ISOLATES AND SELECTION OF THOSE WITH ABILITY TO DEGRADE BA}

Samples from 10 natural vinifications of "Nero di Troia" wines were collected in Apulian wineries. A total of 100 microbial isolates were randomly recovered from the analyzed samples using MRS agar containing cycloheximide in order to inhibit yeasts growth. Following a preliminary Gram stain and catalase reaction, 63 isolates considered as presumptive LAB (i.e., being Gram positive and catalase negative) were selected. These strains were screened by PCR with primers planF and pREV, using L. plantarum WCFS1 as positive control. The amplicon, of approximately $318 \mathrm{bp}$, was present in both the DNA extracted from the positive control and the DNA extracted from 26 of the 63 strains tested. 16S rDNA sequence analysis confirmed that all 26 isolated strains belong to L. plantarum species.

Furthermore, the L. plantarum strains, named NDT with numbers from 01 to 26 , were examined for their ability to degrade histamine, tyramine, cadaverine, and putrescine, the main BA present in wines. Of these, $30.8 \%$ were able to degrade putrescine, $26.9 \%$ tyramine, $19.2 \%$ histamine, and $19.2 \%$ cadaverine. The five strains demonstrating a percentage of BA degradation $>5 \%$ are reported in Table 1. These strains belong to five different vinifications of three diverse wineries. In reason of entity of degradation, L. plantarum NDT 09 (22.12\% of tyramine degraded) and L. plantarum NDT 16 (31.09\% of putrescine degraded) strains were selected as good candidates for further characterization. The presence of the main genes involved in BA production in these two strains was also evaluated. However, none of the L. plantarum strains bacteria analyzed harbor genes involved in BA production (data not shown).

\section{ABILITY OF L. PLANTARUM NDT 09 AND L. PLANTARUM NDT 16 TO DEGRADE TYRAMINE AND PUTRESCINE IN CULTURE MEDIA}

The ability of $L$. plantarum NDT 09 and L. plantarum NDT 16 to degrade tyramine and putrescine was analyzed in 11 of culture medium, also in simultaneous inoculation (Figure 1). After $24 \mathrm{~h}$ of incubation, L. plantarum NDT 09, L. plantarum NDT 16, and NTD 09-NTD 16 co-inoculation showed 22.58, 2.83, and $26.74 \%$ of tyramine degradation respectively (Figure 1). In the case of putrescine the breakdown was $3.53 \%$ for L. plantarum NDT $09,31.43 \%$ for L. plantarum NDT 16 , and $35.28 \%$ for the simultaneous inoculation trial (Figure 1).

\section{ABILITY OF L. PLANTARUM NDT 09 AND L. PLANTARUM NDT 16 TO DEGRADE TYRAMINE AND PUTRESCINE IN PRESENCE OF BA PRODUCERS}

Finally, in order to mimic the real dynamics of production/degradation of tyramine and putrescine, we used the producer strains L. brevis IOEB 9809 (putrescine) and E. faecium OT23 (tyramine), respectively in presence of tyrosine

Table 1 | Degradation (in percentage) of putrescine, tyramine, and histamine by Lactobacillus plantarum strains isolated from wine after $24 \mathrm{~h}$ of culture in MRS broth $(20 \mathrm{ml})$ supplemented with putrescine $(1 \mathrm{mM})$, tyramine $(1 \mathrm{mM})$, histamine $(2.5 \mathrm{mM})$, and cadaverine $(1 \mathrm{mM})$.

Degradation percentage

\begin{tabular}{lllll} 
& Putrescine & Tyramine & Histamine & Cadaverine \\
\hline L. plantarum NDT 03 & 7.15 & n.d. & 8.63 & n.d. \\
L. plantarum NDT 09 & 3.47 & 22.12 & 2.21 & \\
L. plantarum NDT 10 & 11.05 & n.d. & 3.66 & n.d. \\
L. plantarum NDT 16 & 31.09 & 2.75 & 7.49 & 3.41 \\
L. plantarum NDT 21 & 8.72 & 13.33 & 7.19 & 6.68
\end{tabular}

Degradation activity is expressed as a percentage of control without strain. The data presented are mean values from three separate experiments; n.d., no detected effect. 
$\left(15 \mathrm{mmoll}^{-1}\right)$ and agmatine $\left(4.38 \mathrm{mmoll}^{-1}\right.$; Figure 2$)$. Twentyfour hours after inoculation with degrader and producer strains, tyramine and putrescine concentration were lowered to 29.62 and $38.17 \%$ respectively. Moreover, an increase capability to eliminate the BA analyzed was noted when co-inoculation experiments (producers vs. degraders) were performed. The increase degradation of BA observed, could be due to the degradation activity of the $L$. plantarum strains analyzed, but could also be attributable to inhibition phenomena (for example by production of bacteriocins) of the degrader on the producer strains.

\section{SURVIVAL IN WINE-LIKE MEDIUM AND MALOLACTIC FERMENTATION OF L. PLANTARUM NDT 09 AND L. PLANTARUM NDT 16}

In order to analyze the survival and fermentation suitability of L. plantarum strains able to degrade BA, the strains were inoculated in a wine-like medium. The synthetic must was subjected to fermentation by a commercial oenological yeast strain to achieve $12.1 \% \mathrm{v} / \mathrm{v}$ of ethanol content. In three independent experiments, MLF was induced with L. plantarum strains NDT 09 and NDT 16 previously adapted at $\mathrm{pH} 3.5$. The results obtained by the quantification of bacterial biomass and $\mathrm{L}$-malic acid degradation are reported in Figure 3. The sampling times were 0, $1 \mathrm{~h}, 1,2$, $3,7,14$, and 21 days after strain inoculation. Neither degradation of L-malic acid nor spontaneous growth was observed within the control wine (uninoculated wine). The L. plantarum NDT 09 and L. plantarum NDT 16 strains were able to survive in the wine-like medium (Figure 3). An initial decrease in the survival with respect of expected population $\left(2 \times 10^{6} \mathrm{CFU} \mathrm{ml}^{-1}\right)$ was noticed after the inoculation in wine, probably due to the harsh conditions imposed to bacterial cells. Bacterial population remained stable after $1 \mathrm{~h}$. Subsequently, LAB biomass concentration diminished progressively up to the seventh day post inoculation (Figure 3). The strain L. plantarum NDT 16 better survive in wine-like medium than $L$. plantarum NDT 09 (Figure 3). At the 14th day after inoculation, no viable cell was detected. Both strains were found able to degrade L-malic acid. The efficient consumption of this dicarboxylic acid was conducted up to the 14 th day after inoculation (Figure 3). L.

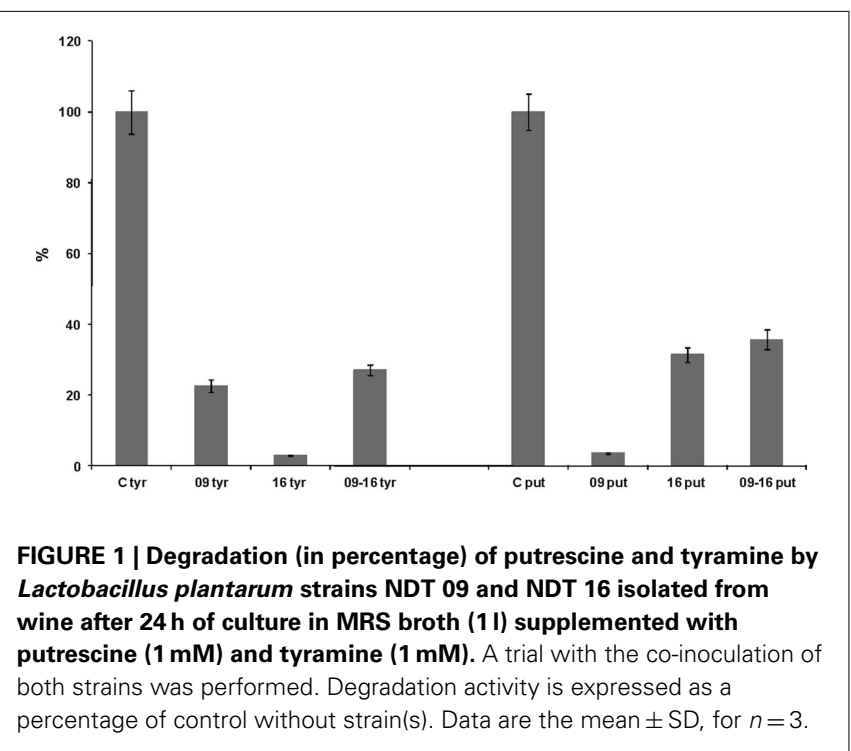

plantarum NDT 16 was found to better degrade L-malic acid than L. plantarum NDT 09. After the 14th day, consistently to the findings in the survival, also L-malic acid degradation stopped. The growth level and the L-malic acid consumption rates showed to be strain-dependent. Overall, the results reported demonstrated that the analyzed strains could be tested as malolactic strains for wine with low L-malic acid contents.

\section{DISCUSSION}

The biotechnological approach reported in this paper, aimed to conciliate malolactic fermentation and BA degradation within the same biotechnological resources: the malolactic starter cultures. The main species involved in malolactic fermentation in wine is Oenococcus oeni. However, as reported by García-Ruiz et al. (2011), in the wine environment, the highest potential for BA degradation among LAB seem to be related to Lactobacillus and Pediococcus species, while O. oeni demonstrated low and rare degradation characteristics (García-Ruiz et al., 2011). In the last years, Lactobacillus spp. received increasing attention as an important resource for the design of a new generation of malolactic fermentation starter cultures (du Toit et al., 2010), insomuch as we found in commerce malolactic starter formulate using L. plantarum V22 strain released in 2010 by Lallemand (Cho et al., 2011; Miller et al., 2011). Other than malic acid decarboxylation, the main advantages of $L$. plantarum employed were: resistance to the stressing wine conditions, production of wine aroma compounds, production of plantaricins, all important factors to compete with spoilage LAB (du Toit et al., 2010).

In this work, we selected two L. plantarum strains (named NDT 09 and NDT 16) from a pool of L. plantarum strains isolated from red wine undergoing malolactic fermentation able to degrade BA such as putrescine and tyramine. The degradation rates observed was higher than that previously reported for $L$. plantarum strains (Leuschner et al., 1998; García-Ruiz et al., 2011). Furthermore, the strains were evaluated in wine-like medium for

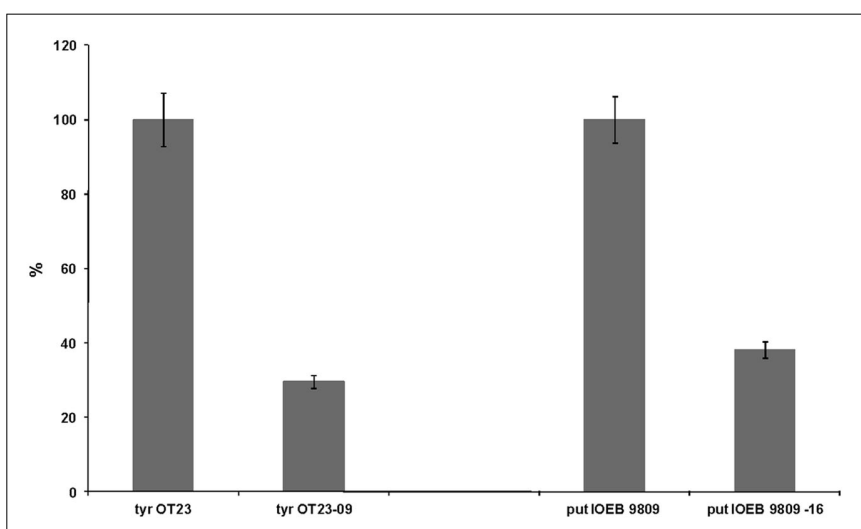

FIGURE 2 | Degradation (in percentage) of putrescine and tyramine by Lactobacillus plantarum strains NDT 09 and NDT 16 in presence of producer strains Lactobacillus brevis IOEB 9809 (putrescine) and Enterococcus faecium OT23 (tyramine), respectively in MRS added with tyrosine $\left(15 \mathrm{mmol} \mathrm{I}^{-1}\right)$ and agmatine $\left(4.38 \mathrm{mmoll}^{-1}\right)$. BA were detected after $24 \mathrm{~h}$ of culture. Degradation activity is expressed as a percentage of control without degrader strain. Data are the mean $\pm S D$, for $n=3$. 


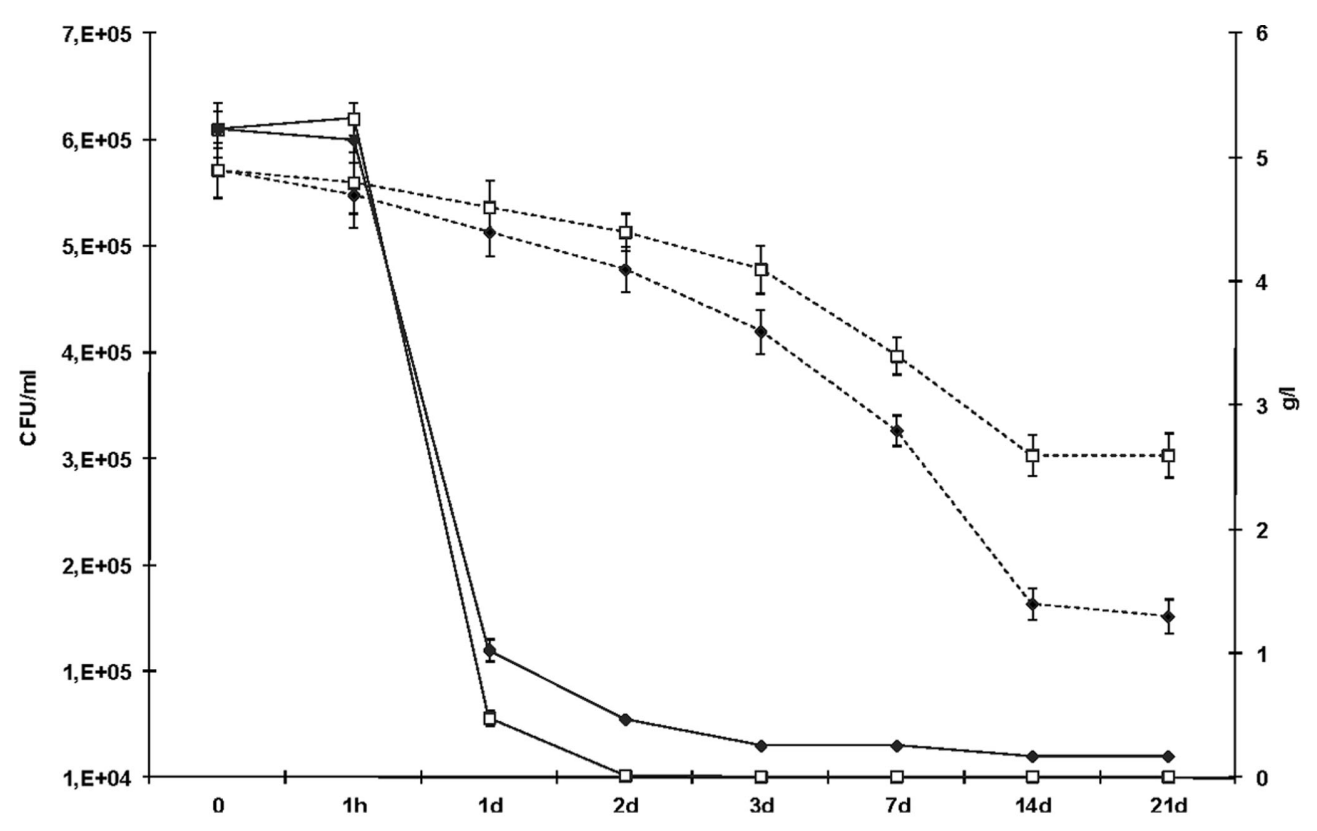

FIGURE 3 | Evolution of the bacterial population during MLF in wine-like medium separately carried out by the two selected Lactobacillus plantarum strains. Samples were taken at the time of inoculation (time zero) and after $1 \mathrm{~h}, 1,2,3,7,14$, and 21 days. L. plantarum NDT 09 (open squares, continuous line) and L. plantarum NDT 16 (filled rhombi, continuous line) counts on de Man Rogosa Sharpe agar were reported in figure. Also the evolution of I-malic acid consumption during MLF was monitored ( $L$. plantarum NDT 09, open squares, dotted line; $L$. plantarum NDT 16, filled rhombi, dotted line). Data are the mean $\pm S D$, for $n=3$, Figure 1. their suitability to degrade malic acid. Although MLF was incompletely performed, the two biotypes showed a respectable aptitude to degrade malic acid, indicating a possible application in reason of wine/must malic acid content. As BA production ability was found to be both species- and strain-dependent (Bover-Cid and Holzapfel, 1999; Russo et al., 2010; Ladero et al., 2012), our work confirmed the scientific evidence indicating a species- and strain dependence also in BA degradation by LAB. Our findings provided the basis for an innovative approach that might be of particular interest for hot climate regions where grapes are harvested at high maturity usually resulting in wine with $\mathrm{pH}$ higher than $\mathrm{pH} 3.5$, high ethanol concentration, low malic acid content, and with considerable spoilage-associated risks. Further studies are ongoing in order to select new L. plantarum strains able to degrade histamine, and to analyze the influence of wine conditions on BA degradation

\section{REFERENCES}

Ali, R.S. (1996). Significance of biogenic amines to food safety and human health. Food Res. Int. 29, 675-690.

Arena, M. P., Romano, A., Capozzi, V., Beneduce, L., Ghariani, M., Grieco, F., Lucas, P., and Spano, G. (2011). Expression of Lactobacillus brevis IOEB 9809 tyrosine decarboxylase and agmatine deiminase genes in wine correlates with substrate availability. Lett. Appl. Microbiol. 53, 395-402.

Arena, M. P., Russo, P., Capozzi, V., Beneduce, L., and Spano, G. (2010).
Effect of abiotic stress conditions on expression of the Lactobacillus brevis IOEB 9809 tyrosine decarboxylase and agmatine deiminase genes. Ann. Microbiol. 61, 179-183.

Beneduce, L., Romano, A., Capozzi, V., Lucas, P., Barnavon, L., Bach, B., Vuchot, P., Grieco, F., and Spano, G. (2010). Biogenic amine in wines. Ann. Microbiol. 60, 573-578.

Bover-Cid, S., and Holzapfel, W. H. (1999). Improved screening procedure for biogenic amine production by lactic acid bacteria. Int. J. Food Microbiol. 53, 33-41.

and malic acid consumption by L. plantarum NDT 09 and L. plantarum NDT 16. Indeed, as indicated by García-Ruiz et al. (2011), wine chemicals such as ethanol (12\%) and polyphenols (75 mg/l), and additives like SO2 $(30 \mathrm{mg} / \mathrm{l})$ may reduce the degrading ability of LAB strains.

\section{ACKNOWLEDGMENTS}

This work was partially funded by the EU commission in the framework of the BIAMFOOD project (Controlling Biogenic Amines in Traditional Food Fermentations in Regional Europe project no 211441) and by the Apulian Region in the framework of the "OenoMicroManagement" project. We would like to thanks "Cantine d'Alfonso del Sordo," "Cantine della Bardulia," "Agricole Alberto Longo," "Cantina Sociale di Barletta," and "Masseria Duca d'Ascoli" for providing wine samples used in this work.

Capozzi, V., Ladero, V., Beneduce, L., Fernández, M., Alvarez, M. A., Benoit, B., Laurent, B., Grieco, F., and Spano, G. (2011). Isolation and characterization of tyramine-producing Enterococcus faecium strains from red wine. Food Microbiol. 28, 434-439.

Capozzi, V., Russo, P., Beneduce, L., Weidmann, S., Grieco, F., Guzzo, J. and Spano, G. (2010). Technological properties of Oenococcus oeni strains isolated from typical southern Italian wines. Lett. Appl. Microbiol. 50, 327-334.
Cho, G.-S., Krauss, S., Huch, M., du Toit, M., and Franz, C. M. A. P. (2011). Development of a quantitative PCR for detection of Lactobacillus plantarum starters during wine malolactic fermentation. J. Microbiol. Biotechnol. 21, 1280-1286

Coton, M., Romano, A., Spano, G., Ziegler, K., Vetrano, C., Desmarias, C., Lonvaud-Funel, A., Lucas, P., and Coton, E. (2010). Prevalence and biodiversity of biogenic amine forming lactic acid bacteria in wine and cider. Food Microbiol. 27, 1078-1085. 
Dapkevicius, M. L. N. E., Nout, M. J. R., Rombouts, F. M., Houben, J. H., and Wymenga, W. (2000). Biogenic amine formation and degradation by potential fish silage starter microorganisms. Int. J. Food Microbiol. 57, 107-114.

du Toit, M., Engelbrecht, L., Lerm, E., and Krieger-Weber, S. (2010). Lactobacillus: the next generation of malolactic fermentation starter cultures - an overview. Food Bioprocess Technol. 4, 876-906.

Edwards, U., Rogall, T., Blöcker, H., Emde, M., and Böttger, E. C. (1989). Isolation and direct complete nucleotide determination of entire genes. Characterization of a gene coding for $16 \mathrm{~S}$ ribosomal RNA. Nucleic Acids Res. 17, 7843-7853.

EFSA Panel on Biological Hazards (BIOHAZ). (2011). Scientific opinion on risk based control of biogenic amine formation in fermented foods. EFSA J. 9, 2393.

García-Ruiz, A., González-Rompinelli, E. M., Bartolomé, B., and MorenoArribas, M. V. (2011). Potential of wine-associated lactic acid bacteria to degrade biogenic amines. Int. J. Food Microbiol. 148, 115-120.

Horton, J. R., Sawada, K., Nishibori, M., and Cheng, X. (2005). Structural basis for inhibition of histamine $\mathrm{N}$ methyltransferase by diverse drugs. J. Mol. Biol. 353, 334-344.

Konakovsky, V., Focke, M., HoffmannSommergruber, K., Schmid, R., Scheiner, O., Moser, P., Jarisch, R., and Hemmer, W. (2011). Levels of histamine and other biogenic amines in high-quality red wines. Food Addit. Contam. Part A Chem. Anal. Control Expo. Risk Assess. 28, 408-416.

Kuefner, M. A., Schwelberger, H. G., Weidenhiller, M., Hahn, E. G., and Raithel, M. (2004). Both catabolic pathways of histamine via histamine-N-methyltransferase and diamine oxidase are diminished in the colonic mucosa of patients with food allergy. Inflamm. Res. 53(Suppl. 1), $\mathrm{S} 31-\mathrm{S} 32$.

Ladero, V., Coton, M., Fernández, M., Buron, N., Martín, M. C., Guichard, H., Coton, E., and Alvarez, M. A. (2011). Biogenic amines content in Spanish and French natural ciders: application of $\mathrm{qPCR}$ for quantitative detection of biogenic amine-producers. Food Microbiol. 28, 554-561.

Ladero, V., Fernández, M., CallesEnríquez, M., Fernández, M., and Alvarez, M. A. (2010). Toxicological effects of dietary biogenic amines. Curr. Nutr. Food Sci. 6, 145-156.

Ladero, V., Fernández, M., CallesEnríquez, M., Sanchez-Llana, E., Cañedo, E., Martín, M. C., and Alvarez, M. A. (2012). Is the production of the biogenic amines tyramine and putrescine a species-level trait in enterococci? Food Microbiol. 30, 132-138.

Latorre-Moratalla, M. L., Bover-Cid, S., Aymerich, T., Marcos, B., VidalCarou, M. C., and Garriga, M. (2007). Aminogenesis control in fermented sausages manufactured with pressurized meat batter and starter culture. Meat Sci. 75, 460-469.

Leroy, F., and De Vuyst, L. (2004). Lactic acid bacteria as functional starter cultures for the food fermentation industry. Trends Food Sci. Technol. $15,67-78$.

Leuschner, R. G., Heidel, M., and Hammes, W. P. (1998). Histamine and tyramine degradation by food fermenting microorganisms. Int. J. Food Microbiol. 39, 1-10.

Lonvaud-Funel, A. (2001). Biogenic amines in wines: role of lactic acid bacteria. FEMS Microbiol. Lett. 199, 9-13.

Lucas, P. M., Blancato, V. S., Claisse, O., Magni, C., Lolkema, J. S., and Lonvaud-Funel, A. (2007). Agmatine deiminase pathway genes in $\mathrm{Lac}$ tobacillus brevis are linked to the tyrosine decarboxylation operon in a putative acid resistance locus. Microbiology 153, 2221-2230.

Martín-Álvarez, P. J., Marcobal, Á. Polo, C., and Moreno-Arribas, $M$ V. (2005). Influence of technological practices on biogenic amine contents in red wines. Eur. Food Res. Technol. 222, 420-424.

Miller, B. J., Franz, C. M. A. P., Cho, G.S., and du Toit, M. (2011). Expression of the malolactic enzyme gene (mle) from Lactobacillus plantarum under winemaking conditions. Curr. Microbiol. 62, 1682-1688.

Naila, A., Flint, S., Fletcher, G., Bremer, P., and Meerdink, G. (2010). Control of biogenic amines in food - existing and emerging approaches. J. Food Sci. 75, R139-R150.

Russo, P., Spano, G., Arena, M. P. Capozzi, V., Grieco, F., and Beneduce, L. (2010). Are consumers aware of the risks related to biogenic amines in food? Curr. Res. Technol. Educ. Top. Appl. Microbiol. Microb. Biotechnol. 2, 1087-1095.

Smit, A. Y., du Toit, W. J., and du Toit, M. (2008). Biogenic amines in wine: understanding the headache. S. Afr. J. Enol. Vitic. 29, 109-127.

Spano, G., Russo, P., Lonvaud-Funel, A. Lucas, P., Alexandre, H., Grandvalet, C., Coton, E., Coton, M., Barnavon, L., Bach, B., Rattray, F., Bunte, A., Magni, C., Ladero, V., Alvarez, M., Fernández, M., Lopez, P., de Palencia, P F., Corbi, A., Trip, H., and Lolkema, J. S. (2010). Biogenic amines in fermented foods. Eur. J. Clin. Nutr. 64, 95-100.
Suzzi, G., and Gardini, F. (2003). Biogenic amines in dry fermented sausages: a review. Int. J. Food Microbiol. 88, 41-54.

Torriani, S., Felis, G. E., and Dellaglio, F. (2001). Differentiation of Lactobacillus plantarum, L. pentosus, and L. paraplantarum by $r e c A$ gene sequence analysis and multiplex PCR assay with $r e c A$ gene-derived primers. Appl. Environ. Microbiol. 67, 3450-3454.

Zimatkin, S. M., and Anichtchik, O. V. (1999). Alcohol-histamine interactions. Alcohol 34 141-147.

Conflict of Interest Statement: The authors declare that the research was conducted in the absence of any commercial or financial relationships that could be construed as a potential conflict of interest.

Received: 13 February 2012; paper pending published: 04 March 2012; accepted: 14 March 2012; published online: 02 April 2012.

Citation: Capozzi V, Russo P, Ladero V, Fernández $M$, Fiocco D, Alvarez $M A$, Grieco $F$ and Spano $G$ (2012) Biogenic amines degradation by Lactobacillus plantarum: toward a potential application in wine. Front. Microbio. 3:122. doi: 10.3389/fmicb.2012.00122

This article was submitted to Frontiers in Food Microbiology, a specialty of Frontiers in Microbiology.

Copyright (c) 2012 Capozzi, Russo, Ladero, Fernández, Fiocco, Alvarez, Grieco and Spano. This is an open-access article distributed under the terms of the Creative Commons Attribution Non Commercial License, which permits noncommercial use, distribution, and reproduction in other forums, provided the original authors and source are credited. 